\title{
Enzyme-Linked Immunosorbent Assay for Detection of Escherichia coli Heat-Labile Enterotoxin
}

\author{
ROBERT H. YOLKEN, ${ }^{1 *}$ HARRY B. GREENBERG,${ }^{1}$ MICHAEL H. MERSON,${ }^{3}$ R. BRADLEY SACK, ${ }^{2}$ \\ AND ALBERT Z. KAPIKIAN ${ }^{1}$ \\ Laboratory of Infectious Diseases, National Institute of Allergy and Infectious Diseases, National Institutes \\ of Health, Bethesda, Maryland 20014'; Department of Infectious Diseases, Johns Hopkins University, \\ Baltimore, Maryland 21211'; and Center for Disease Control, Atlanta, Georgia 30333 3
}

Received for publication 13 July 1977

The development of an enzyme-linked immunosorbent assay (ELISA) for the detection of heat-labile Escherichia coli enterotoxin is described. The assay, which is based on the immunological similarity between Vibrio cholerae toxin and heat-labile $E$. coli enterotoxin, is similar in design to a radioimmunoassay but utilizes enzyme-labeled rather than radioactive isotope-labeled reagents. The ELISA system is as sensitive as both radioimmunoassay and the $y-1$ adrenal cell assay for the detection of heat-labile $E$. coli enterotoxin but requires neither radioactive reagents nor tissue culture techniques. The ELISA is easy to perform and is adaptable for use in small laboratories.

Enterotoxigenic strains of Escherichia coli are a major cause of diarrheal disease in humans (17). These strains elaborate at least two toxins, both of which can cause diarrheal disease. One form of toxin is heat stable, has a low molecular weight, and appears to be nonantigenic (14). The other form is heat labile, has a molecular weight of greater than 30,000 , and is immunologically related to the enterotoxin of Vibrio cholerae in that antitoxin directed against $V$. cholerae will also neutralize the heat-labile toxin (HLT) that is produced by $E$. coli $(8,18)$. In the past, the identification of enteropathic $E$. coli has been based on serotyping. However, recent reports indicate that HLT may be produced by serotypes of $E$. coli not previously thought to be pathogenic, and the value of serotyping is being questioned (9). Thus, it is important to have a means of detecting HLT directly. This detection is most commonly accomplished in bioassay systems such as rabbit ileal loop (2), infant rabbit (11), rabbit skin (6), Chinese hamster ovary cell (12), or y-1 adrenal cell (3) assays. Although these assays can be specific and sensitive, they are often difficult to perform and require a continuous supply of viable biological tissue. The lack of general availability of these bioassay systems in most centers has hampered the study of the role of HLT in human illness (7).

A solid-phase radioimmunoassay (RIA) for the detection of HLT has been recently described (10). This assay makes use of the crossreactivity between HLT produced by $E$. coli and toxin produced by $V$. cholerae. However, the requirement for radioactive reagents and an expensive detection system makes the RIA impractical for many centers. Recently, the enzyme-linked immunosorbent assay (ELISA) has been shown to be a sensitive technique for the detection of several infectious agents (19-21). ELISA, which utilizes an enzyme rather than a radioactive isotope as the immunoglobulin marker, has the advantages over RIA that radioactive reagents are not required and the end point is a visible color change. In this report we describe the use of ELISA in the detection of HLT produced by $E$. coli.

\section{MATERIALS AND METHODS}

High-titered antisera to $V$. cholerae toxin (kindly provided by John Robbins, Bureau of Biologics, Bethesda, Md.) was produced as previously described (1). Guinea pig antisera to $V$. cholerae toxin were produced by repeated inoculations of purified toxin (Schwarz/Mann, Orangeburg, N.Y.) into guinea pigs The immunization schedule was as follows: day 1,10 $\mu \mathrm{g}$ of cholera toxin in complete Freund adjuvant injected subcutaneously; day $21,10 \mu \mathrm{g}$ of cholera toxin in incomplete Freund adjuvant (subcutaneously); day $35,10 \mu \mathrm{g}$ of cholera toxin in saline (subcutaneously) day 49 , sera harvested.

Goat anti-guinea pig serum was obtained commercially (Antibodies Inc., Davis, Calif.) and conjugated with alkaline phosphatase (Sigma type VII) by the method of Engvall and Perlmann, using 2 mg of antiguinea pig globulin with $1,000 \mathrm{U}$ of enzyme (19).

$E$. coli colonies were isolated from 93 stool specimens from adults with gastroenteritis in Bangladesh and from Peace Corps volunteers with gastroenteritis in Kenya (10). Colonies of $E$. coli were selected at random and inoculated into screw-top tubes (13 by 
$100 \mathrm{~mm}$ ) containing $3.0 \mathrm{ml}$ of Trypticase soy broth

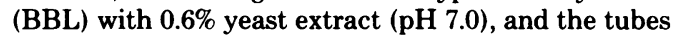
were placed in a roller drum turning at $22 \mathrm{rpm}$. After growth for 18 to $24 \mathrm{~h}$ at $37^{\circ} \mathrm{C}$, the cultures were centrifuged at $12,000 \times g$ for $30 \mathrm{~min}$, and the supernatant was assayed for HLT by the $y-1$ adrenal cell assay (3) and for heat-stable toxin by the infant mouse assay (15). The same supernatant fluids were also tested by ELISA. In addition, lypholized filtrates from broth cultures of HLT-producing $E$. coli that had been isolated in several parts of the world were tested by ELISA. These preparations had also been tested by RIA and rabbit ileal loop assay.

The ELISA method used was modified from that of Voller et al. (19). The optimal dilutions of reagents were first determined by checkerboard titration. The method used is outlined schematically in Fig. 1. The burro anti-cholera serum was diluted 1:10,000 in car-

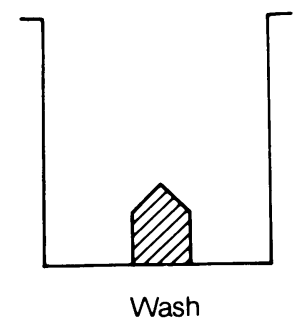
A. Burro anti-cholera toxin is absorbed to the well.

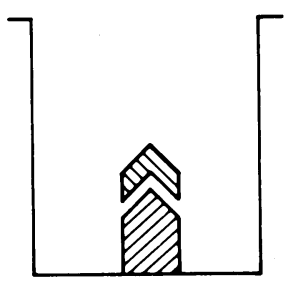

B. A sample of broth is added to the well and diluted with an equal volume PBS-Tween. If heat-labile enterotoxin is present in the broth it will react with the anti-toxin already absorbed to the well. The Tween serves to prevent non-specific absorbtion.

Wash

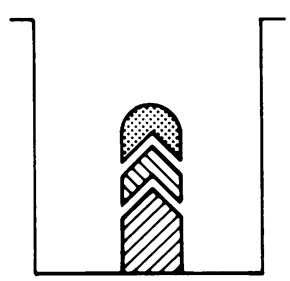

C. An alliquot of guinea pig anti-cholera toxin is added. This will react with any heat-labile toxin attached to the solid phase in step B.

Wash

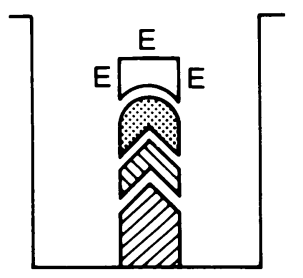

D. An alliquot of alkaline phosphatase linked anti-guinea pig serum is added. This will attach to any guinea pig serum attached to the solid phase in step $C$.

Wash

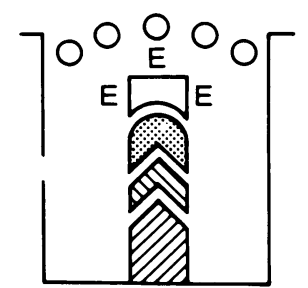

E. Substrate solution is added. If there is any alkaiine phosphatase attached to the solid phase it will convert the colorless substrate to a yellow solution which can be detected by a colorimeter or by the naked eye.

FIG. 1. Schematic diagram of ELISA for detection of HLT (modified from Voller et al. [19]). 
bonate buffer ( $\mathrm{pH} \mathrm{9.6),} \mathrm{and} 0.1 \mathrm{ml}$ of the solution was added to each well of a polyvinyl, round-bottom, microtiter plate (Dynatech Industries, Alexandria, Va.) and allowed to incubate at $4^{\circ} \mathrm{C}$ for 14 to $16 \mathrm{~h}$. The plates were then washed three times with a solution of phosphate-buffered saline containing $0.5 \mathrm{ml}$ of polysorbate (Tween 20 ) per liter (PBS-Tween). The plates were stored in a moist chamber until use.

A $0.050-\mathrm{ml}$ sample of $\boldsymbol{E}$. coli supernatant was added to the precoated well and diluted with an equal volume of PBS-Tween. After an incubation of 14 to $16 \mathrm{~h}$ at $25^{\circ} \mathrm{C}$, the plate was washed three times with PBSTween, and a 0.1-ml sample of guinea pig anti-cholera serum diluted $1: 2,000$ in PBS-Tween containing $1 \%$ normal burro serum was added. After a 1-h incubation at $37^{\circ} \mathrm{C}$, the plates were again washed three times in PBS-Tween, and a 0.1-ml sample of alkaline phosphatase-labeled anti-guinea pig globulin diluted 1:400 in PBS-Tween containing $1 \%$ normal burro serum was added. After another $1-\mathrm{h}$ incubation at $37^{\circ} \mathrm{C}$, the plates were washed three times in PBS-Tween, and a solution containing $1 \mathrm{mg}$ of $p$-nitrophenyl phosphate per ml (Sigma 104 phosphate substrate) was added. After an incubation of $30 \mathrm{~min}$ at ambient temperature, the amount of yellow color produced by the interaction of the substrate with the enzyme bound to the solid phase was determined. Spectrophotometric measurements were performed by means of a photometer, which determines the optical density, at a wavelength of $400 \mathrm{~nm}$, of the substrate solution in each well of a microtiter plate (21). A positive/negative $(P / N)$ value was determined by dividing the optical density of the sample by the optical density of a known negative broth. A P/N value of 2.0 or greater was considered to be positive for the presence of $\operatorname{HLT}(20,21)$.

Visual readings were performed by comparing, with the naked eye, the amount of yellow color in a specimen well with that of a well containing a known negative broth. A specimen was considered to be positive if it clearly was more yellow than the standard. All specimens were processed under code, with the key to the code being held outside of the laboratory performing the ELISA.

Miniplate method. In an attempt to decrease the time required for the detection of HLT by the ELISA system, a miniplate method was devised. Organisms were grown in syncase media for $48 \mathrm{~h}$ at $37^{\circ} \mathrm{C}(16)$ in the wells of a microtiter plate that had been pretreated with burro anti-cholera serum as described above. After $48 \mathrm{~h}$ of growth, the plates were washed three times in PBS-Tween and processed for ELISA as above. To test the feasibility of transporting the miniplates, the cultures were grown in the wells in one laboratory, and the plates were washed and transported to another laboratory $\mathbf{4 0}$ miles away.

\section{RESULTS}

Toxin preparations. The ELISA was capable of detecting cholera toxin at a concentration of $0.1 \mathrm{pg} / \mathrm{ml}$. This sensitivity is comparable to that of RIA (Fig. 2). In terminal dilution experiments with a standard preparation of $E$. coli HLT (derived from organism 408-3), the ELISA and RIA had equal sensitivities (Fig. 3). In ad- dition, lyophilized filtrates from HLT-producing $E$. coli isolated in several parts of the world were tested by ELISA. The data presented in Fig. 4 demonstrate that the amount of HLT detected by ELISA was proportional to that found by the rabbit ileal loop assay. However the ELISA system was approximately 50 times more sensitive than the rabbit ileal loop assay.

Clinical specimens. Broth cultures of isolates from 93 patients were studied by ELISA. Of these, 47 had HLT detected by the $y-1$ adrenal cell assay. Of these 47,6 had HLT alone whereas 41 also had heat-stable toxin detected by the infant mouse assay. Of the 46 specimens negative for HLT by the $y-1$ adrenal cell assay,

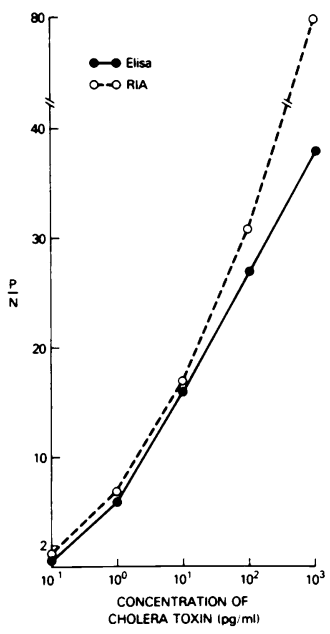

FIG. 2. Relative sensitivity of ELISA and RIA for detection of purified cholera toxin (Schwarz/Mann).

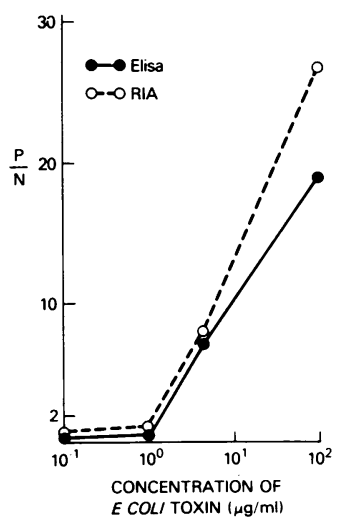

FIG. 3. Sensitivity of ELISA and RIA for detection of a crude preparation of heat-labile $E$. coli. Toxin was obtained from a broth culture. Concentration is expressed as micrograms per milliliter of bacterial protein. 
6 had heat-stable toxin detected by the infant mouse assay whereas 40 had no demonstrable toxin.

There was perfect concordance between ELISA positivity, as determined by a $P / N$ value of greater than 2.0, and the presence of HLT by the y-1 adrenal cell assay (Fig. 5). Specimens that contained only heat-stable toxin were not

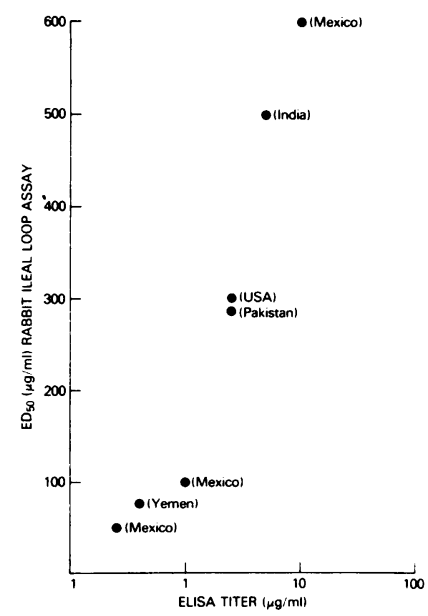

FIG. 4. Comparison of the toxin activity of seven broth filtrates from various toxigenic $E$. coli isolates, using ELISA and rabbit ileal loop assays. Titers were determined by serial dilutions and were based on the dry weight of the lypholized broth filtrates. The country of origin of the filtrate is indicated in parentheses.

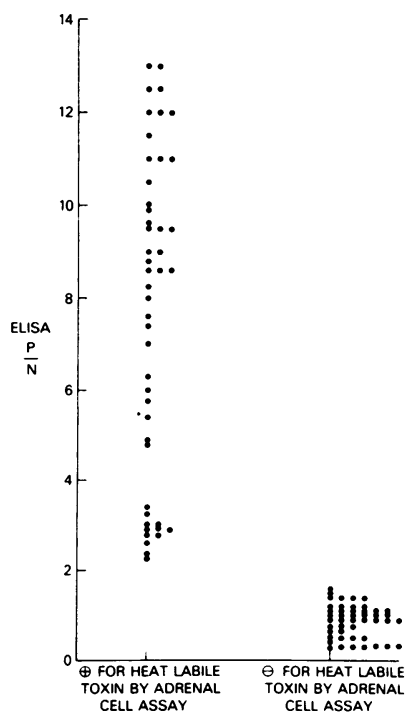

Fig. 5. Results of ELISA for HLT, using broths obtained after growing the E. coli in tubes placed overnight in a roller drum. positive by ELISA. The ELISA positivity was removed by heating at $70^{\circ} \mathrm{C}$ for $30 \mathrm{~min}$, confirming that the substance measured was, in fact, heat labile.

When visual readings were used to determine ELISA positivity, HLT was correctly detected in 46 of 47 specimens positive by the $y-1$ adrenal cell assay. The one false-negative specimen had a $P / N$ value of 2.1 , the lowest in the series. There were no false-positive readings (Table 1).

Miniplate method. A total of 44 specimens were grown in pretreated wells as described above. Of these, 21 had HLT demonstrable by the $y-1$ adrenal cell assay, 6 had heat-stable toxin demonstrable by the infant mouse assay but did not have HLT, and 17 had no demonstrable toxin. The ELISA results, as determined both by $P / N$ values and visual readings, were completely concordant with the results of the y-1 adrenal cell assay (Fig. 6).

\section{DISCUSSION}

ELISA appears to be as sensitive as the $y-1$ adrenal cell assay for the detection of HLT produced by $E$. coli. In addition, the specificity of the ELISA system was demonstrated by the

TABLE 1. Comparison of the detection of $E$. coli HLT by y-1 adrenal cell assay and ELISA, using visual readings ${ }^{a}$

\begin{tabular}{ccc}
\hline $\begin{array}{c}\text { Toxin detected by adrenal } \\
\text { cell assay }\end{array}$ & $\begin{array}{c}\text { Toxin detected by ELISA } \\
\text { Yes }\end{array}$ & No \\
\hline Yes & 46 & 1 \\
No & 0 & 46 \\
\hline
\end{tabular}

${ }^{a}$ Bacteria were grown using the roller drum method.

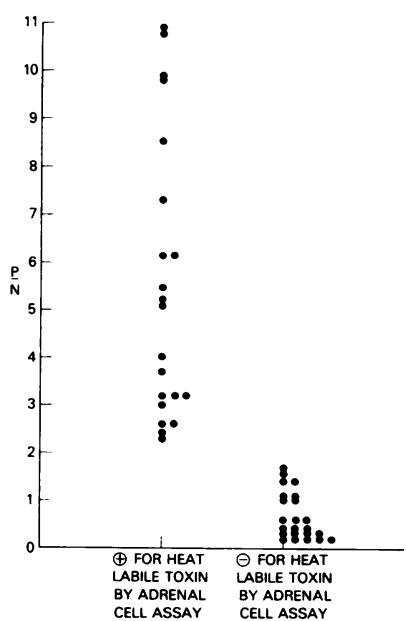

Fig. 6. Results of ELISA for HLT, using the miniplate method. 
fact that strains of $E$. coli that did not produce HLT were negative by ELISA.

The method described in this report differs from that of other ELISA systems developed for antigen detection (19-21) in that it utilizes two antibodies, with the second linked to the enzyme. This two-antibody technique was developed because we found that a single-antibody technique, similar to that used to detect hepatitis B virus (20), was not sufficiently sensitive to detect small amounts of HLT. However, the ELISA performed as described above was able to detect cholera toxin at a level of $0.1 \mathrm{pg} / \mathrm{ml}$, the same level as the RIA system (10). In addition, this ELISA was able to detect HLT as well as both the RIA and the $y-1$ adrenal cell systems. Our level of detection exceeded that of Holmgren and Svennerholm, who were able to detect cholera toxin only at a level of $0.09 \mu \mathrm{g} / \mathrm{ml}$ utilizing an ELISA-blocking system (13).

Another advantage of the use of a two-antibody system is that a single labeled antibody, in this case anti-guinea pig globulin, can be used in a variety of tests in which unlabeled guinea pig antibodies are utilized.

One potential disadvantage of a two-antibody system is that there can be nonspecific reactions. For example, the labeled anti-guinea pig globulin could react with the burro serum that is used to precoat the well. We found that these nonspecific reactions could be prevented by diluting the reagents in normal burro serum.

The y-1 adrenal cell assay has been shown to be an effective tool for the detection of HLT (3, $15,16)$. However, this method requires the maintenance of a viable cell line and personnel trained in the interpretation of the test. There are similar limitations to other bioassay systems (7). A recently described RIA (10) overcomes the problems of maintaining a viable cell line but requires radioactive reagents and an expensive radiation detection device, thus making the system impractical for many centers. Recently, Evans et al. described a passive immune hemolysis test for the detection of $\operatorname{HLT}(4,5)$. Although this system overcomes some of the problems discussed above, the method appears more difficult to perform than ELISA and requires either purified HLT or an antibody directed against it, reagents that are not generally available. In addition, a continuous supply of fresh sheep erythrocytes and complement is needed for this system.

ELISA, on the other hand, uses no unstable reagents and, if visual readings are used, no specialized equipment is required. If the miniplate method is used, centrifugation is not required and specimens may be transported to central laboratories without loss of activity. It is hoped that by the use of ELISA the epidemiology and pathophysiology of gastroenteritis caused by toxigenic $E$. coli can be further elucidated.

\section{ACKNOWLEDGMENTS}

We thank Alan Zulich, Annie Vaughn, and Nancy Lloyd for technical assistance, Robert M. Chanock for his review of the manuscript, and Barbara Armiger for secretarial assistance.

\section{LTTERATURE CITED}

1. Dafni, Z., and J. B. Robbins. 1976. Purification of heatlabile enterotoxin from Escherichia coli $078: \mathrm{H} 11$ by affinity chromatography with antisera to Vibrio cholerae toxin. J. Infect. Dis. 133(Suppl.):S138-S141.

2. De, S. W., K. Bhattacharya, and S. Sarkar. 1956. A study of the pathogenicity of strains of Bacterium coli. J. Pathol. Bacteriol. 71:201-209.

3. Donta, S., and D. Smith. 1974. Stimulation of steroidogenesis in tissue culture by enterotoxigenic Escherichia coli and its neutralization by specific antiserum. Infect. Immun. 9:500-505.

4. Evans, D. J., and D. G. Evans. 1977. Direct serological assay for the heat-labile enterotoxin of Escherichia coli, using passive immune hemolysis. Infect. Immun. 16:604-609.

5. Evans, D. J., and D. G. Evans. 1977. Inhibition of immune hemolysis: a serological assay for heat-labile enterotoxin of Escherichia coli. J. Clin. Microbiol. 5:100-105.

6. Evans, D. J., D. G. Evans, and S. L. Gorbach. 1973 Production of vascular permeability factor by enterotoxigenic Escherichia coli isolated from man. Infect. Immun. 8:725-730.

7. Farmer, J. J., III, B. R. Davis, W. B. Cherry, D. J. Brenner, V. R. Dowell, Jr., and A. Balows. 1977. "Enteropathogenic serotypes" of Escherichia coli which really are not. J. Pediatr. 90:1047-1049.

8. Finkelstein, R. A., M. K. LaRue, D. W. Johnston, M. L. Vasil, G. J. Cho, and J. R. Jones. 1975. Isolation and properties of heat-labile enterotoxins from enterotoxigenic Escherichia coli. J. Infect. Dis. 133(Suppl.):S120-S137.

9. Gangarosa, E. J., and M. H. Merson. 1977. Epidemiologic assessment of the relevance of so-called enteropathogenic serogroups of Escherchia coli in diarrhea. N. Engl. J. Med. 296:1210-1213.

10. Greenberg, H. B., D. A. Sack, W. Rodriguez, R. B. Sack, R. G. Wyatt, A. R. Kalica, R. L. Horswood, R. M. Chanock, and A. Z. Kapikian. 1977. A microtiter solid-phase radioimmunoassay for detection of Escherichia coli heat-labile enterotoxin. Infect. Immun. 17:541-545.

11. Gorbach, S. L., and C. M. Kharana. 1972. Toxigenic Escherichia coli. N. Engl. J. Med. 287:791-795.

12. Guerrant, R. L, L. L. Branton, T. C. Schartman, L. I. Rebhum, and A. G. Gilman. 1974. Cyclic adenosine monophosphate and alteration of Chinese hamster ovary cell morphology: a rapid, sensitive in vitro assay for the enterotoxins of Vibrio cholerae and Escherichia coli. Infect. Immun. 10:320-327.

13. Holmgren, J., and A.-M. Svennerholm. 1973. Enzymelinked immunosorbent assays for cholera serology. Infeet. Immun. 7:759-763.

14. Jacks, T. M., and B. J. Wi. 1971. Biochemical properties of Escherichia coli low-molecular-weight heat-stable enterotoxin. Infect. Immun. 9:342-347.

15. Morris, G. K., M. H. Merson, D. A. Sack, J. G. Wells, W. T. Martin, W. E. DeWitt, J. C. Feeley, R. B. Sack, and D. M. Bessudo. 1976. Laboratory investi- 
gation of diarrhea in travellers to Mexico: evaluation of methods for detecting enterotoxigenic Escherichia coli. J. Clin. Microbiol. 3:486-495.

16. Sack, D. A., and R. B. Sack. 1975. Test for enterotoxigenic Escherichia coli using y-1 adrenal cells in miniculture. Infect. Immun. 11:334-336.

17. Sack, R. B. 1975. Human diarrheal disease caused by enterotoxigenic Escherichia coli. Annu. Rev. Microbiol. 29:333-353.

18. Smith, N. W., and R. B. Sack. 1973. Immunologic crossreactions of enterotoxins from Escherichia coli and Vibrio cholerae. J. Infect. Dis. 127:164-170.

19. Voller, A., D. Bidwell, and A. Bartlett. 1976. Micro- plate enzyme immunoassays for the immunodiagnosis of virus infections, p. 506-512. In N. Rose and H. Friedman (ed.), Manual of clinical immunology. American Society for Microbiology, Washington, D.C.

20. Wolters, G., L. Kuijpers, J. Kacaki, and A. Schuurs. 1976. Solid phase enzyme-immunoassay for detection of hepatitis B surface antigen. J. Clin. Pathol. 29:873-879.

21. Yolken, R. H., H. W. Kim, T. Clem, R. Wyatt, A. Kalica, R. Chanock, and A. Z. Kapikian. 1977. Enzyme linked immunosorbent assay ELISA for detection of human reovirus-like agent of infantile gastroenteritis. Lancet ii:263-266. 